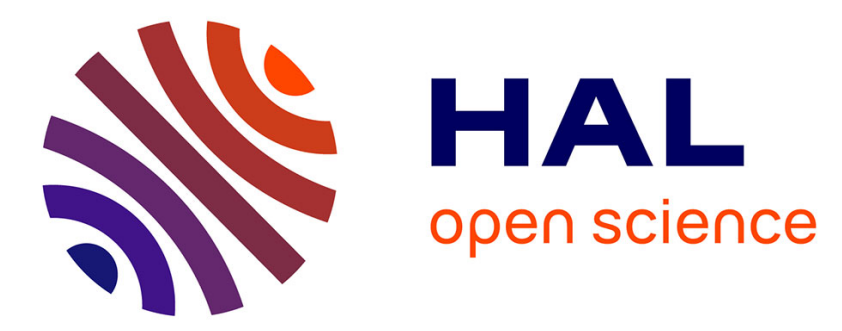

\title{
Bat sonar and wing morphology predict species vertical niche
}

Charlotte Roemer, Aurélie Coulon, Thierry Disca, Yves Bas

\section{To cite this version:}

Charlotte Roemer, Aurélie Coulon, Thierry Disca, Yves Bas. Bat sonar and wing morphology predict species vertical niche. Journal of the Acoustical Society of America, 2019, 145 (5), pp.3242-3251. 10.1121/1.5102166 . hal-02563996

\section{HAL Id: hal-02563996 \\ https://hal.science/hal-02563996}

Submitted on 5 May 2020

HAL is a multi-disciplinary open access archive for the deposit and dissemination of scientific research documents, whether they are published or not. The documents may come from teaching and research institutions in France or abroad, or from public or private research centers.
L'archive ouverte pluridisciplinaire $\mathbf{H A L}$, est destinée au dépôt et à la diffusion de documents scientifiques de niveau recherche, publiés ou non, émanant des établissements d'enseignement et de recherche français ou étrangers, des laboratoires publics ou privés. 
1 Title: Bat sonar and wing morphology predict species vertical niche

2 Running title: Bat traits predict species vertical niche

3

4 Charlotte Roemer

5 Current address: Biotope, 22 bd Maréchal Foch, Mèze, France

6 Also at: Centre d'Ecologie et des Sciences de la Conservation (CESCO), Muséum national

7 d'Histoire naturelle, Centre National de la Recherche Scientifique, Sorbonne Université, CP

$8 \quad$ 135, 57 rue Cuvier 75005 Paris, France

9 Also at: CEFE, CNRS, Univ Montpellier, Univ Paul Valéry Montpellier 3, EPHE, IRD, 1919

10 route de Mende, Montpellier, France

12 Aurélie Coulon

13 Current address: Centre d'Ecologie et des Sciences de la Conservation (CESCO), Muséum

14 national d'Histoire naturelle, Centre National de la Recherche Scientifique, Sorbonne

15 Université, CP 135, 57 rue Cuvier 75005 Paris, France

16 Also at: CEFE, CNRS, Univ Montpellier, Univ Paul Valéry Montpellier 3, EPHE, IRD, 1919

17 route de Mende, Montpellier, France

19 Thierry Disca

20 Biotope, 22 bd Maréchal Foch, Mèze, France 
23 Current address: Centre d'Ecologie et des Sciences de la Conservation (CESCO), Muséum

24 national d'Histoire naturelle, Centre National de la Recherche Scientifique, Sorbonne 25 Université, CP 135, 57 rue Cuvier 75005 Paris, France

26 Also at: CEFE, CNRS, Univ Montpellier, Univ Paul Valéry Montpellier 3, EPHE, IRD, 1919 27 route de Mende, Montpellier, France

\section{ABSTRACT}

The use of echolocation allows insectivorous bats to access unique foraging niches by

31 locating obstacles and prey with ultrasounds in complete darkness. To avoid interspecific

32 competition, it is likely that sonar features and wing morphology co-evolved with species

33 vertical distribution, but due to the technical difficulties of studying flight in the vertical

34 dimension, this has never been demonstrated with empirical measurements.

35 We equipped 48 wind masts with arrays of two microphones and located the vertical 36 distribution of a community of 19 bat species and two species groups over their annual 37 activity period ( $>8,000$ nights). We tested the correlation between the proportion of flights at 38 height and the acoustic features of bat calls as well as their wing morphology.

39 We found that call peak frequency and bandwidth are good predictors of bat use of the 40 vertical space regardless of their acoustic strategies (i.e. gleaning, hawking or detecting prey 41 flutter). High wing aspect ratios and high wing loadings were associated with high 42 proportions of time spent at height, confirming hypothesis from the literature. 


\section{Keywords}

Wing aspect ratio; echolocation; bat vertical space use; acoustic location.

\section{INTRODUCTION}

Insectivorous bat species have developed through evolution the ability to commute and forage in complete darkness. Although feeding on similar resources (i.e. insects), most sympatric species specialise in their prey selection and therefore in their habitat selection, while some are more plastic (Dietz et al., 2009). In order to match these particular needs, this diet partitioning is accompanied by morphological and behavioural differences. Illustrating those differences, Myotis nattereri, a small bat (wingspan $=250-300 \mathrm{~mm}$ ), is able to forage insects resting on leaves under the forest cover while Tadarida teniotis, a large bat (wingspan $=400$ $450 \mathrm{~mm}$ ), forages on insect swarms in wide and elevated open spaces (Arthur and Lemaire, 2015). In addition, the echolocation system, developed through evolution to sense the environment in the dark, reflects the ability of each species to perceive obstacles and prey (Collen, 2012; Schnitzler et al., 2003; Siemers and Schnitzler, 2004).

Indeed, bat echolocation calls are designed in such a way that most species may be differentiated from one another using call peak frequency, duration and bandwidth or call shape, despite some overlap (Barataud, 2015; Fenton and Bell, 1981). Frequency in echolocation calls varies from $9 \mathrm{kHz}$, as in calls emitted by Euderma maculatum, Vespertilionidae (Fullard and Dawson, 1997) or Tadarida teniotis, Molossidae (Arlettaz, 1990), to $212 \mathrm{kHz}$, emitted by Cloeotis percivali, Hipposideridae (Fenton and Bell, 1981). Because atmospheric attenuation increases with call frequency, low frequency signals carry 
through greater distances than high frequencies, which in turn procure the advantage of a higher structure resolution (Pye, 1979). On the other hand, low frequencies are associated with long wavelengths, which are unsuitable for the detection of targets such as small insects, and should be the major evolutionary constraint for the use of low frequencies in echolocation (Barclay and Brigham, 1991; Waters et al., 1995). Echolocation call length varies from $1 \mathrm{~ms}$ as by Myotis brandtii, Vespertilionidae, to more than $80 \mathrm{~ms}$ by Rhinolophus ferrumequinum, Rhinolophidae (Barataud, 2015). Long calls allow a better detection of faint and distant echoes through the repeated addition of signal information that evokes the activity of neurons tuned to the frequency of interest, and consequently increase echolocation ranges (Neuweiler, 1989; Schnitzler et al., 2003). Long calls can also provide information on prey fluttering and movement directionality (Trappe and Schnitzler, 1982), while the emission of short calls decrease the issue of call-echo overlap (Jones, 1999). Finally, call bandwidth varies from less than $1 \mathrm{kHz}$, as by Nyctalus noctula, Vespertilionidae (Barataud, 2015), to more than $170 \mathrm{kHz}$ in some Kerivoula species (Vespertilionidae) (Kingston et al., 1999). Large bandwidths enhance range accuracy and resolution (i.e. the differentiation of two targets at close distances) (Pye, 1979; Siemers and Schnitzler, 2004) while small bandwidths, combined with long call length, can also be used to detect prey fluttering or increase the detection range.

Aldridge and Rautenbach (1987) studied the links between call shape, wing morphology, manoeuvrability, habitat use and diet in South African insectivorous bats. They found that the differences in acoustic features and wing morphology explained resource partitioning in these species. High wing loading (larger wing area relative to mass) generally correlates with high flight speed while low wing loading favours good manoeuvrability, essential when foraging in clutter (Kalko et al., 2008; Norberg and Rayner, 1987). In addition, high wing aspect ratio (narrow wings) generally correlates with decreases in transport costs thanks to a low wing inertia, and favours good agility at high speeds (Kalko et al., 2008; Norberg and Rayner, 
1987). These studies highly contributed to the understanding of the acoustic and morphologic characteristics leading to clutter - or closed - versus open space adaptations in bats (Fenton, 1990). Several other studies also found strong relationships between body size or mass and acoustic parameters in many bat species all over the world (Bogdanowicz et al., 1999; Jones, 1999; Penone et al., 2018; Thiagavel et al., 2017). These findings highlight the co-evolution of many traits in bats.

In 2001, Schnitzler and Kalko described the concept of bat guilds, which was refined over time (Denzinger and Schnitzler, 2013; Denzinger et al., 2018). Guilds may be used to form consistent species groups for the study of sonar structures, habitat types, diet, foraging modes and other traits. In Denzinger et al. (2018), four guilds may be distinguished according to their acoustic strategies: (1) aerial hawkers or trawlers developed a strategy to efficiently locate prey in open and edge space using long quasi-constant frequency (QCF) calls (2) active gleaners mostly use short calls with high frequency compounds and frequency modulated (FM) calls resulting in large bandwidths, useful to detect prey or obstacles in high clutter (3) passive gleaners also use short calls with high frequencies and FM calls, but mostly listen to the rustling sounds of their prey while foraging, and use echolocation for orientation (4) some species also use a strategy implying long constant frequency calls with modulated frequency components (CF-FM) at high frequencies which allow them to evaluate flutter information from the prey returning echoes.

Associations in echolocation, wing morphology and flight behaviour have only been demonstrated for adaptation to clutter (Aldridge and Rautenbach, 1987; Siemers and Schnitzler, 2004), from studies using material positioned at ground level, with a limited detection range, while bats use a three-dimensional space that can be as elevated as $3000 \mathrm{~m}$ for some species (Peurach, 2003; Williams et al., 1973). The association between bat sonar or 
115 wing morphology and their use of the vertical dimension has never been thoroughly

116 demonstrated. Since the vertical distribution of insects varies according to species (Reynolds 117 et al., 2017), and since bats differentiate in their diets (Dietz et al., 2009), the vertical 118 distribution of the different bat guilds is strongly expected to follow that of their prey 119 (Norberg and Rayner, 1987; Roeleke et al., 2018). Roemer et al. (2017) showed that bat 120 guilds according to Denzinger and Schnitzler (2013) could be ordered along the gradient of 121 the rate of time spent at height. It was also shown that the occurrence of certain insect orders 122 in bat diet could be associated with certain bat sonar and morphology features (Bogdanowicz 123 et al., 1999). However, the contribution of sonar features and wing morphology to the vertical 124 separation of species was only described from case studies on target species, or from a 125 collection of heterogeneous observations (visual, mistnetting, acoustic) of a bat community 126 (Banse, 2010; Denzinger et al., 2018; Kalko et al., 2008), and remains to be demonstrated with empirical and standardised measurements.

128 The study of animal use of the vertical space is a challenging task because of the technical 129 difficulties this implies. Stereoscopic cameras are best suited for studies in a restricted volume 130 because field of view is limited (Holderied and Jones, 2009). Tracking of animal movements 131 with radar units only allow poor taxonomic resolution because target echoes provide limited 132 information on animal size and flight behaviour (Bruderer and Popa-Lisseanu, 2005). 133 Acoustic tracking of animal echolocation calls offers numerous advantages, such as species 134 identification with the acoustic clues of their calls, an omnidirectional detection range, and an 135 easy automation of the process (Holderied et al., 2008; Koblitz, 2018; Roemer et al., 2017). In 136 addition, the installation of microphone arrays on wind masts allows acoustic location in a 137 space situated at dozens of meters above ground, that is otherwise difficult to access (Roemer 138 et al., 2017). 
139 The aim of our study was to investigate the links between the vertical distribution of a

140 community of European insectivorous bats, the acoustic parameters of their sonar (peak

141 frequency, call duration and call bandwidth) and their wing morphology (wing aspect ratios

142 and wing loading). We expected (1) longer call durations to be associated with higher flight

143 heights, (2) higher peak frequencies to be associated with lower flight heights, (3) larger

144 bandwidths to be associated with lower flight heights, (4) narrower wings to be associated

145 with higher flight heights and (5) higher wing loadings to be associated with higher flight

146 heights. To measure bat position in the vertical space, we equipped wind masts with

147 microphone arrays and performed acoustic location of bat echolocation calls.

\section{MATERIAL \& METHODS}

150 A. Acoustic recordings used to study bat altitudinal behaviour

151 Between 2011 and 2017, recordings were conducted at 48 sites in France and Belgium where 152 bat activity was monitored on 8,435 nights $($ mean $=175.7$ standard deviation $=76.1$, min $=$

$15319, \max =352$ nights per site). Microphones were installed on lattice or monopole wind masts 154 of 50-100 $\mathrm{m}$ in height and the wind masts themselves were erected in open or semi-open 155 habitats (i.e. agricultural land, bocage, garrigue, wetlands or forest clearing). Arrays 156 composed of two microphones were achieved with two SMX-US, SMX-U1 (Wildlife 157 Acoustics, USA) or SMX-US (Biotope, France) microphones plugged to an SM2BAT or 158 SM3BAT (all models, Wildlife Acoustics, Massachusetts, USA). Microphones were inserted 159 into tubes, facing downward, to protect them from weather elements. A custom-made 160 aluminium reflector placed below the microphone at a $45^{\circ}$ angle minimised the directionality 161 of the setting. Microphones were installed at heights ranging from 4 to $85 \mathrm{~m}$ (Figure 2 in 162 suppl. mat.). Recorders were programmed to start each day 30 min before sunset and stop 
16330 min after sunrise. Whole night recordings were performed on study sites between 2013 and

1642017 (38 sites), but from 2011 and 2012 (10 sites) samplings were collected for 10 minutes

165 every 20 minutes. Gain was set at $36 \mathrm{~dB}$, sampling rate at $192 \mathrm{kHz}$, trigger at $6 \mathrm{~dB}$ above

166 background noise and trigger window at $2.5 \mathrm{sec}$. A $1 \mathrm{kHz}$ high pass filter was used. Files were

167 compressed in WAC4 format and analysed in WAV format or directly recorded in WAV

168 format.

169 B. Species identification and flight height classification

170 Files were decompressed with the WAC2WAV or the Kaleidoscope software (Wildlife

171 Acoustics, Massachusetts, USA). Files were automatically cut in 5 second bouts after each

172 triggered recording to be used as a proxy for a bat pass (Barré et al., 2018; Roemer et al.,

173 2017). SonoChiro (Biotope, France) was used to automatically attribute calls to a species or a

174 species group, and the verification of the result was done by manually checking acoustic

175 sequences.

176 To identify bat species based on acoustic features, we followed the method developed by

177 Barataud (2015), which is the most extensive study of European bat calls published today.

178 Identification criteria are based on the association between acoustic call type, call shapes and

179 measurable parameters (initial frequency, terminal frequency, signal length, maximum energy

180 and its repartition ...), their rhythms (interval duration between calls) and the environment

181 (distance to obstacles). With the knowledge accumulated today, this method allows the

182 identification of 29 species out of the 34 extant in France and Belgium under good recording

183 conditions. If a bat was recorded at both microphones at the same time, we checked the

184 sequence which contained the most calls, and that was thus supposed to display the best

185 acoustic quality. 
Some sequences may only contain faint calls, and yet contain enough clues to attribute the

187 sequence to a species, because the species does not completely overlap the acoustic repertoire

188 of another species (e.g. low frequency calls of Tadarida teniotis or low frequency calls of Hypsugo savii). Call duration and bandwidth are the most affected by atmospheric attenuation, yet other call parameters that are better preserved are sometimes sufficient to make an identification (e.g. peak frequency, inter-call duration, frequency modulation (i.e.

192 shape) of the main part of the call). Yet, some sequences were so affected by atmospheric attenuation that there was no sufficient clue to attribute the sequence to a species. In addition, some species use sonar calls that are sometimes very close, even identical in certain flight circumstances, preventing identification to species level. These acoustic sequences that could not be identified at the species level were either classed in a group of species - when the vertical flight behaviours of all species were equivalent within the same group - or left unidentified and not used for further analysis (8.4\% of all bat passes). Here, Myotis myotis and M. blythii were identified as the "large Myotis" group, all other Myotis as the "small Myotis" group, and all Plecotus calls to the Plecotus spp. group. Species within those two groups present flight heights comparable to the other species of their group (Rodrigues et al., 2015), and similar acoustic features (Barataud, 2015). Great care must be taken in the analysis of the results of the species $P$. kuhlii and P. nathusii, because acoustic features of these two species are simultaneously very variable and similar to each other. $V$. murinus is also difficult to distinguish from $N$. leisleri, but $V$. murinus is known to be rare in France and Belgium.

207 each call started on each microphone. We then obtained the time differences of arrival 208 (TOAD) for each call detected using the find.matches function of Hmisc package (Harrell, 2018) from R (R Core Team, 2014). With two microphones, flight height cannot be precisely

210 calculated, and TOAD were used to determine to which microphones bats were closer. A 
211 height threshold was defined for each site as the median height between the two microphones.

212 Microphone median height was variable depending on study site (20-50 m) (Figure 2), but

213 this variation did not greatly affect species proportion of flight at height (Figure 3). Using this

214 threshold, bat calls were assigned to two classes following the method described in Roemer et 215 al. (2017): "at height" if the source of the signal was above the threshold and "at ground 216 level" if it was below the threshold. A ratio of the time spent at height was then calculated for 217 each species. It must be noted that in forest clearings, tree canopy was never higher than the 218 median height between both microphones. Therefore, bats positioned "at height" were flying 219 in an open environment.

220 A generalised linear mixed model (GLMM) was used to estimate rates of flight at height for 221 each species. Bat pass height was modelled as a binomial variable (at height or at ground 222 level) according to species as a fixed effect. The median height of microphones was 223 introduced as a fixed effect to control for its potential influence. The local environment effect 224 on flight behaviour was taken into account by introducing study sites as a random variable. 225 The GLMM was built using the glmmTMB function (Magnusson et al., 2018) of R (R Core 226 Team, 2014).

We chose to study the three main features defining bat call shapes and acoustic properties, namely call duration, peak frequency (i.e. the frequency at the maximum energy), and 230 bandwidth. We referred to the work of Barataud $(2017,2015)$ to obtain the mean values of 231 these three acoustic parameters for the species recorded in our study (Table 1). In the group 232 small Myotis, we present results for M. daubentonii, M. nattereri and M. bechsteinii, which 233 were the most common Myotis identified in our recordings. In the same manner, in the group 234 Plecotus spp., we present results for P. auritus and P. austriacus. 
236 We calculated indices of wing morphology based on bone measurements, which are the most 237 practical and consistent indices, following the method of Bader et al. (2015). All 238 morphological information was retrieved from Dietz et al. (2009). The latter authors provided 239 the minimum and maximum values per species, from which we calculated a mean value that 240 we used for further analyses.

$$
\text { Aspect Ratio Index } A R I=\frac{d 3+F A}{d 5},
$$

241 where $\mathrm{FA}=$ length of the forearm, $\mathrm{d} 3=$ length of the third digit and $\mathrm{d} 5=$ length of the fifth 242 digit.

$$
\text { Wing Loading Index } W L I=\frac{m}{(F A+d 3) \times d 5 \times 2} \text {, }
$$

243 where $\mathrm{m}=$ body mass.

244 E. Correlations between rate of flight at height and species traits

245 We first checked for normality in the distribution of raw or transformed variables. Most 246 variables did not follow a normal distribution, hence the correlations between each pair of 247 variables were tested with a Kendall correlation test. For data visualisation, we assigned 248 species into exclusive frequency-modulated (FM), constant-frequency with modulated 249 frequency components $(\mathrm{CF}+\mathrm{FM})$ and frequency-modulated or quasi-constant frequency 250 (FM/QCF) categories, according to their acoustic strategies (Barataud, 2015). 
253 In total, 639,734 bat passes were recorded. Table 1 shows bat passes identified at the species

254 or species group level. There was a continuous gradient in the vertical distribution of species 255 from Rhinolophus bats that were never located at height to Vespertilio murinus that was 256 located $86 \%$ of the time at height. Rhinolophus, Barbastella, Plecotus, Myotis, Miniopterus 257 species and Pipistrellus pygmaeus were located less than $5 \%$ of the time at height. Eptesicus 258 serotinus, E. nilsonii, Hypsugo savii, P. kuhlii, P. pipistrellus and P. nathusii were located 259 between 5 and $25 \%$ of the time at height. Nyctalus, Tadarida and Vespertilio species were 260 located more than $30 \%$ of the time at height.

261 A. Interdependence of traits

262 Correlation tests for all species showed that all morphological and acoustic features were 263 inter-correlated, except for call peak frequency versus call duration (Table 2).

264 B. Correlations between proportion of flight at height and traits

265 Morphological and acoustic features were all correlated to the proportion of flights at height 266 (Table 3, Figure 1). Compared to low-flying species, high-flying species used lower peak 267 frequencies, narrower bandwidths, longer calls, and possessed narrower wings with higher 268 wing loadings (Figure 1). In the correlation between the rate of flight at height and call 269 duration, Rhinolophus species stood as outliers because they use extremely long call duration 270 compared to other species flying near ground level (Figure 1b). Concerning call bandwidth, 271 Myotis species were the outliers because they use extremely large bandwidth compared to 272 other species flying near ground level (Figure 1c). 
275 A. Acoustic location from wind masts, a powerful tool for the study of animal flight behaviour

277 We studied to what extent the prevalence of bat species at elevated heights can be predicted 278 by the acoustic features of their sonar and by their wing morphology. In the past, a study by 279 Jensen and Miller (1999) with a vertical array of three microphones on a 15 meter pole 280 elucidated the links between echolocation features and flight height in E. serotinus, a 281 European bat. A study by Kloepper and Kinniry (2018) suggested that the features of 282 echolocation calls in Tadarida brasiliensis, an American bat, vary in function of their flight 283 height. However, our study is the first to assess this relationship in a bat community. The use 284 of wind masts allowed a long-term monitoring of bat flight behaviour and an objective 285 assessment of species vertical flight distribution. The automation of the process allowed us to 286 equip 48 masts over the French and Belgian territories and analyse their results. The 287 combination of long-term monitoring and of the high amount of study sites was an advantage 288 in obtaining enough data for rare species (e.g. E. nilssonii) or species with short detection 289 ranges (e.g. $R$. hipposideros).

290 B. Bat traits predict bat vertical niche partitioning

291 We demonstrate for the first time that the acoustic features of bat sonar predict bat vertical 292 distribution regardless of species acoustic strategies. Call duration was a less reliable 293 predictor than call peak frequency and bandwidth since Rhinolophidae stood as outliers with a 294 very long call duration and an exclusive presence at ground level. This particularity is 295 explained by their echolocation strategy to detect prey flutter by emitting long constant 296 frequencies (CF) calls carrying short frequency modulated (FM) signals with a high duty 297 cycle (Schnitzler and Denzinger, 2011). Rhinolophidae are part of the Yinpterochiroptera 
suborder, that diverged 60 mya from the Yangochiroptera, (Teeling, 2009), to which the other

299 bat families addressed here belong.

300 Our study also shows the first correlations based on empirical measures between bat wing morphology and their vertical distribution. It confirmed our hypotheses that narrow wings with high wing loadings are best suited for flying at greater heights.

In the bat community that we sampled, the proportion of time spent at height might be 304 correlated to the availability in the prey on which each species specialises, but the 305 opportunistic high-flying species (e.g. Nyctalus, Tadarida) could also exploit more elevated 306 altitudes to actively avoid spatial competition with other species (Dietz et al., 2009; Roeleke 307 et al., 2018). Indeed, the low frequency calls providing long detection ranges to high-flying 308 bats are also less effective in detecting the small prey they feed on than the high frequency 309 calls of species found at lower heights (e.g. Pipistrellus) (Waters et al., 1995).

We show that the use of the vertical space in European bats is ordered from Rhinolophus 312 species (always flying near ground level or near background) to Nyctalus and Tadarida 313 species (prevailing at height). In fact, guild categories used to define bat adaptation to clutter 314 (i.e. narrow, edge and open space foragers (Denzinger and Schnitzler, 2013)) may be ordered 315 along this same gradient from narrow foragers (low-flying species) to open space foragers 316 (high-flying species). Manoeuvrability and the challenging detection of very thin obstacles, or 317 prey at a very small distance from background elements seem to be the main issues limiting 318 species foraging success when flying through cluttered environments (Fenton et al., 2016; 319 Norberg and Rayner, 1987; Sleep and Brigham, 2003). On the other hand, it is interesting to 320 discuss what limits the ability of bats to reach elevated heights. 
In the first instance, we demonstrated that high-flying species possess high aspect ratios and

322 high wing loadings. For foraging purposes, high-flyers cover greater distances than low-flyers

323 (Dietz et al., 2009), possibly because insects are scarcer at height (Reynolds et al., 2017).

324 Economic flights over long distances are facilitated by a low wing inertia, which is associated

325 with a high aspect ratio (Norberg and Rayner, 1987; Pennycuick, 2008). Since high aspect

326 ratios are often associated with short wings, high-flyers tend to also have high wing loadings

327 (Norberg and Rayner, 1987). In order to sustain a powered flight, species with higher wing

328 loadings must fly faster, which is precisely an optimal strategy when travelling through long

329 distances between two foraging grounds (Grodzinski et al., 2009; Norberg and Rayner, 1987),

330 but also for long-distance migration (Hedenström, 2009). It was suggested that the swift

331 aspect of Miniopterus schreibersii could be linked to agile flight in high-altitude hawking

332 (Norberg and Rayner, 1987). Our results do not support this hypothesis, since this species was very rarely recorded at height. The relatively high aspect ratio of $M$. schreibersii is probably associated with good agility during fast flights near ground level. This species indeed covers very long distances overnight (up to $40 \mathrm{~km}$ ) to actively avoid intraspecific competition for

336 food in the vicinity of its very large colonies (Dietz et al., 2009). As a fast flyer (Holderied 337 and Jones, 2009), this species does not have a higher wing loading than the average, because 338 its wings are longer than average due to the unusual length of its third digit, but its wide 339 uropatagium allows for a manoeuvrability not seen in other species with narrow wings (Dietz 340 et al., 2009).

341 In the second instance, we demonstrated that high-flying bats use shallower - and generally 342 longer - calls than low flying species. This call structure carries signals through greater 343 distances than high frequencies because it is more tolerant to atmospheric attenuation (Pye, 344 1979). It can be argued that small bats have difficulties producing low frequency echolocation 345 calls since their production requires large body structures, and species are therefore limited by 
their laryngeal capacity (Metzner and Müller, 2016; Pye, 1979). Several studies indeed found

347 that body size is inversely correlated with echolocation call peak frequency - when acoustic

348 strategies are taken into account - which corroborates this hypothesis (Bogdanowicz et al.,

349 1999; Jones, 1999; Penone et al., 2018; Thiagavel et al., 2017). Calls used for social

350 communication may be much lower than the echolocation repertoire (Chaverri et al., 2018),

351 but their production is based on the same biomechanical properties of the larynx than the

352 production of echolocation calls (Kobayasi et al., 2012). Indeed, in isolated larynxes, it was

353 demonstrated that below a certain air flow threshold, the emitted frequencies correspond to

354 the register of echolocation frequencies, but passing this threshold, the emitted frequencies

355 correspond to the register of social communication (much lower frequencies) (Kobayasi et al.,

356 2012). This jumping from one frequency register to another is similar to yodelling.

357 Nonetheless, we found that species with high-pitched vocalisations (e.g. Myotis sp. or M.

358 schreibersii) could also - although rarely - be found at elevated heights. These individuals

359 either came from the foot of the mast and flew to the top of the mast, a behaviour which was

360 showed in B. barbastellus (Budenz et al., 2017), or they were already flying at height when

361 they came across the wind mast. Individuals can lower their call frequency to perceive

362 obstacles from a greater distance (Jensen and Miller, 1999; Schaub and Schnitzler, 2007),

363 however we do not expect species such as Myotis sp. to be able to modify their sonar in such a

364 way that they could perceive ground level when flying at more than $20 \mathrm{~m}$, their estimated

365 maximal detection range in open spaces (Barataud, 2015). High-pitched echolocators are

366 more likely to explore wind masts from the bottom, but they could possibly rely only on

367 vision to perceive long-distance obstacles and use their sonar to sense small obstacles such as

368 other flying animals (Boonman et al., 2013).

D. Conclusion and perspectives 
Our study contributes to the comprehension of bat use of the vertical dimension, which is

371 often difficult to explore due to technical limitations. We demonstrated that bat vertical niche partitioning is not only constrained by species ability to move and detect prey in cluttered environments, but it is also constrained by their ability to commute and forage at elevated heights with optimal flight energetic costs and with sonar adaptations for long-distance perception of their environment. There are probably many other morphologic traits that were not tested in our study and that may be correlated with species use of the vertical space. For example, long and narrow pinnae (external ears) or tragi (small eminence of the external ear), possibly accounting for the accuracy of vertical localization (Fenton et al., 2016), are generally found in low flyers, while short and round pinnae and tragi are found in bats 380 prevailing at height (see Dietz et al., 2009).

381 Sonar features do not only vary interspecifically, and individuals can indeed adapt call 382 frequency, duration and bandwidth to commute or forage in different environments (Barataud, 2015; Moss and Surlykke, 2001; Russo et al., 2017). Studies on E. serotinus and V. murinus (QFC strategy) show that their repertoire is quite variable up to a dozen meters from the background, and then stabilises past that threshold (Jensen and Miller, 1999; Schaub and

386 Schnitzler, 2007). However, it is not known whether this holds true for other echolocating 387 strategies (e.g. FM and CF-FM) and to what extent bat flight height may be predicted intraspecifically from sonar features.

The use of the aerosphere by bats makes them vulnerable to anthropogenic activities such as

390 planes and wind turbines (Voigt et al., 2018). It was shown that bat species susceptibility to 391 collisions with wind turbines is correlated to their proportion of time spent at height (Roemer 392 et al., 2017). This classification of species susceptibility is of great importance in wind turbine 393 impact assessment studies, which rely on the estimation of bat local abundance to estimate 
394 future impacts. However, this classification is only available for European bats and requires 395 important time and human investments to be established for different bat communities. The 396 correlation between species traits and proportion of flight at height presented in the current 397 study should provide a proxy to predict species relative susceptibility to wind turbines in other 398 geographical areas.

\section{ACKNOWLEDGMENTS}

401 402 403

This study was a collaboration between Biotope and the French Muséum national d'Histoire naturelle in the form of a $\mathrm{PhD}$ thesis funded by Biotope and the Association Nationale de la Recherche et de la Technologie. We would like to thank Sébastien Devos, Marie-Lilith Patou, Julien Mérot, Alexandre Haquart, Julien Tranchard, Philippe Ferragne, Matthieu Guyot, Antonin Dhellemme, Matthieu Lageard, Paul Gillot, François Huchin, Julien Renglet, Magali Argaud and Estelle Cleach for their important contributions to equipment design and installation, data collection and acoustic analysis. We thank Ugo Schumpp for the infography of bat wings. We are grateful to Yann Gager for his help in finding appropriate references in the literature, and to Jean-François Julien, whose insightful comments improved the manuscript. We thank Marja Roemer for proofreading the manuscript as well as two anonymous reviewers for their comments.

\section{REFERENCES}

Aldridge, H. D. J. N., and Rautenbach, I. L. (1987). "Morphology, Echolocation and Resource Partitioning in Insectivorous Bats,” J. Anim. Ecol., 56, 763. doi:10.2307/4947 
Arlettaz, R. (1990). “Contribution à l'éco-éthologie du Molosse de Cestoni, Tadarida teniotis (Chiroptera), dans les Alpes valaisannes (sud-ouest de la Suisse)," " Contribution to the eco-ethology of the European free-tailed bat, Tadarida teniotis (Chiroptera, Molossidae), in the Alps of the Valais (south-western Switzerland)," Z. Für Säugetierkd., 55, 28-42.

Arthur, L., and Lemaire, M. (2015). Les chauves-souris de France, Belgique, Luxembourg et Suisse, Bats of France, Belgium, Luxemburg and Switzerland, Biotope Editions, Mèze; Paris, 544 pages.

Bader, E., Jung, K., Kalko, E. K., Page, R. A., Rodriguez, R., and Sattler, T. (2015). "Mobility explains the response of aerial insectivorous bats to anthropogenic habitat change in the Neotropics," Biol. Conserv., 186, 97-106.

Banse, G. (2010). “Ableitung des Kollisionsrisikos von Fledermäusen an Windenergieanlagen über biologische Parameter," "Calculation of bat collision risks at wind turbines using biological parameters" Nyctalus NF, 15, 64-74.

Barataud, M. (2015). Acoustic ecology of European bats: species identification, study of their habitats and foraging behaviour, Biotope éditions, 344 pages.

Barataud, M. (2017, January). "Update of the 3rd edition (2015) of Acoustic ecology of European bats http://ecologieacoustique.fr/?page_id=1713 consulted on the 10/03/2018.," Retrieved from http://ecologieacoustique.fr/?page_id=1713

Barclay, R. M., and Brigham, R. M. (1991). "Prey detection, dietary niche breadth, and body size in bats: why are aerial insectivorous bats so small?," Am. Nat., 137, 693-703.

Barré, K., Le Viol, I., Bas, Y., Julliard, R., and Kerbiriou, C. (2018). "Estimating habitat loss due to wind turbine avoidance by bats: Implications for European siting guidance," Biol. Conserv., 226, 205-214. 
440 Bogdanowicz, W., Fenton, M. B., and Daleszczyk, K. (1999). "The relationships between echolocation calls, morphology and diet in insectivorous bats,” J. Zool., 247, 381-393. doi:10.1111/j.1469-7998.1999.tb01001.x

443

444

445

446

447

448

449

450

451

452

453

454

455

456

457

458

459

460

461

462

463

464

Boonman, A., Bar-On, Y., and Yovel, Y. (2013). "It's not black or white- on the range of vision and echolocation in echolocating bats," Front. Physiol., , doi: 10.3389/fphys.2013.00248. doi:10.3389/fphys.2013.00248

Bruderer, B., and Popa-Lisseanu, A. G. (2005). "Radar data on wing-beat frequencies and flight speeds of two bat species," Acta Chiropterologica, 7, 73-82. doi:10.3161/17335329(2005)7[73:RDOWFA]2.0.CO;2

Budenz, T., Gessner, B., Lüttmann, J., Molitor, F., Servatius, K., and Veith, M. (2017). “Up and down: B barbastellus explore lattice towers," Hystrix, 28, 272-276.

Chaverri, G., Ancillotto, L., and Russo, D. (2018). "Social communication in bats," Biol. Rev.,.

Collen, A. (2012). The evolution of echolocation in bats: a comparative approach (Doctoral dissertation), University College London.

Denzinger, A., and Schnitzler, H.-U. (2013). "Bat guilds, a concept to classify the highly diverse foraging and echolocation behaviors of microchiropteran bats," Front. Physiol., , doi: 10.3389/fphys.2013.00164. doi:10.3389/fphys.2013.00164

Denzinger, A., Tschapka, M., and Schnitzler, H.-U. (2018). "The role of echolocation strategies for niche differentiation in bats," Can. J. Zool., 96, 171-181. doi:10.1139/cjz-2017-0161

Dietz, C., Nill, D., and Helversen, O. von (2009). Bats of Britain, Europe and Northwest Africa, A \& C Black, 406 pages.

Fenton, B. (1990). “The foraging behaviour and ecology of animal-eating bats," Can. J. Zool., 68, 411-422. 
Fenton, M. B., and Bell, G. P. (1981). "Recognition of Species of Insectivorous Bats by Their Echolocation Calls,” J. Mammal., 62, 233-243. doi:10.2307/1380701

Fenton, M. B., Grinnell, A., Popper, A. N., and Fay, R. R. (Eds.) (2016). Bat bioacoustics, Springer handbook of auditory research, Springer Science+Business Media, New York, 304 pages.

Fullard, J. H., and Dawson, J. W. (1997). "The echolocation calls of the spotted bat Euroderma maculatum are relatively inaudible to moths,” J. Exp. Biol., 200, 129-137.

Grodzinski, U., Spiegel, O., Korine, C., and Holderied, M. W. (2009). “Context-dependent flight speed: evidence for energetically optimal flight speed in the bat Pipistrellus kuhlii ?," J. Anim. Ecol., 78, 540-548. doi:10.1111/j.1365-2656.2009.01526.x

Harrell, F. E. (2018). Hmisc: Harrell Miscellaneous,. Retrieved from https://CRAN.Rproject.org/package $=$ Hmisc

Hedenström, A. (2009). “Optimal migration strategies in bats,” J. Mammal., 90, 1298-1309.

Holderied, M. W., Baker, C. J., Vespe, M., and Jones, G. (2008). "Understanding signal design during the pursuit of aerial insects by echolocating bats: tools and applications," Integr. Comp. Biol., 48, 74-84.

Holderied, M. W., and Jones, G. (2009). "Flight Dynamics,” Ecol. Behav. Methods Study Bats,.

Jensen, M. E., and Miller, L. A. (1999). "Echolocation signals of the bat Eptesicus serotinus recorded using a vertical microphone array: effect of flight altitude on searching signals,” Behav. Ecol. Sociobiol., 47, 60-69. doi:10.1007/s002650050650

Jones, G. (1999). “Scaling of echolocation call parameters in bats,” J. Exp. Biol., 202, 33593367. 
Kalko, E. K., Estrada Villegas, S., Schmidt, M., Wegmann, M., and Meyer, C. F. (2008). "Flying high—assessing the use of the aerosphere by bats," Integr. Comp. Biol., 48, 60-73.

Kingston, T., Jones, G., Akbar, Z., and Kunz, T. H. (1999). "Echolocation signal design in Kerivoulinae and Murininae (Chiroptera: Vespertilionidae) from Malaysia.,"

Kloepper, L. N., and Kinniry, M. (2018). "Recording animal vocalizations from a UAV: bat echolocation during roost re-entry," Sci. Rep., 8, 7779.

Kobayasi, K. I., Hage, S. R., Berquist, S., Feng, J., Zhang, S., and Metzner, W. (2012). "Behavioural and neurobiological implications of linear and non-linear features in larynx phonations of horseshoe bats," Nat. Commun., 3, 1184.

Koblitz, J. C. (2018). "Arrayvolution-Using microphone arrays to study bats in the field," Can. J. Zool.,.

Magnusson, A., Skaug, H., Nielsen, A., Berg, C., Kristensen, K., Maechler, M., Bentham, K. van, et al. (2018). glmmTMB: Generalized Linear Mixed Models using Template Model Builder,. Retrieved from https://CRAN.R-project.org/package=glmmTMB

Metzner, W., and Müller, R. (2016). "Ultrasound production, emission, and reception," Bat Bioacoustics, Springer, pp. 55-91.

Moss, C. F., and Surlykke, A. (2001). “Auditory scene analysis by echolocation in bats,” J. Acoust. Soc. Am., 110, 2207-2226. doi:10.1121/1.1398051

Neuweiler, G. (1989). "Foraging Ecology and Audition in Echolocating Bats," Trends Ecol. Evol., 4, 7.

Norberg, U. M., and Rayner, J. M. (1987). "Ecological morphology and flight in bats (Mammalia; Chiroptera): wing adaptations, flight performance, foraging strategy and echolocation," Phil Trans R Soc Lond B, 316, 335-427.

Pennycuick, C. J. (2008). Modelling the flying bird, Elsevier, Vol. 5. 
513 Penone, C., Kerbiriou, C., Julien, J.-F., Marmet, J., and Le Viol, I. (2018). "Body size 514 information in large-scale acoustic bat databases," PeerJ, 6, e5370. doi:10.7717/peerj.5370

516 Peurach, S. C. (2003). "High-altitude Collision between an Airplane and a Hoary Bat, Lasiurus cinereus," Bat Res. News, 44, 2-3.

518 Pye, J. D. (1979). “Why ultrasound?,” Endeavour, 3, 57-62.

$519 \mathrm{R}$ Core Team (2014). $R$ : A language and environment for statistical computing, R Foundation for Statistical Computing, Vienna, Austria. Retrieved from http://www.R-project.org/

Reynolds, D. R., Chapman, J. W., and Drake, V. A. (2017). "Riders on the Wind: The Aeroecology of Insect Migrants,” In P. B. Chilson, W. F. Frick, J. F. Kelly, and F. Liechti (Eds.), Aeroecology, Springer International Publishing, Cham, pp. 145-178. doi:10.1007/978-3-319-68576-2_7

Roeleke, M., Johannsen, L., and Voigt, C. C. (2018). "How Bats Escape the Competitive 526 Exclusion Principle-Seasonal Shift From Intraspecific to Interspecific Competition Drives Space Use in a Bat Ensemble," Front. Ecol. Evol., , doi: 10.3389/fevo.2018.00101. doi:10.3389/fevo.2018.00101

Roemer, C., Disca, T., Coulon, A., and Bas, Y. (2017). "Bat flight height monitored from wind masts predicts mortality risk at wind farms," Biol. Conserv., 215, 116-122. doi:10.1016/j.biocon.2017.09.002

Russo, D., Ancillotto, L., and Jones, G. (2017). "Bats are still not birds in the digital era: echolocation call variation and why it matters for bat species identification," Can. J. Zool., 96, 63-78. doi:10.1139/cjz-2017-0089

Schaub, A., and Schnitzler, H. U. (2007). "Echolocation behavior of the bat Vespertilio murinus reveals the border between the habitat types 'edge' and 'open space,"' Behav. Ecol. Sociobiol., 61, 513-523. doi:10.1007/s00265-006-0279-9 
538 Schnitzler, H.-U., and Denzinger, A. (2011). "Auditory fovea and Doppler shift compensation: adaptations for flutter detection in echolocating bats using CF-FM signals,” J. Comp. Physiol. A, 197, 541-559.

Schnitzler, H.-U., and Kalko, E. K. V. (2001). "Echolocation by Insect-Eating Bats," BioScience, 51, 557. doi:10.1641/0006-3568(2001)051[0557:EBIEB]2.0.CO;2

Schnitzler, H.-U., Moss, C. F., and Denzinger, A. (2003). "From spatial orientation to food acquisition in echolocating bats," Trends Ecol. Evol., 18, 386-394. doi:10.1016/S0169-5347(03)00185-X

Siemers, B. M., and Schnitzler, H.-U. (2004). "Echolocation signals reflect niche differentiation in five sympatric congeneric bat species," Nature, 429, 657-661. doi:10.1038/nature02547

Sleep, D. J., and Brigham, R. M. (2003). “An experimental test of clutter tolerance in bats,” J. Mammal., 84, 216-224.

Teeling, E. C. (2009). "Hear, hear: the convergent evolution of echolocation in bats?," Trends Ecol. Evol., 24, 351-354.

Thiagavel, J., Santana, S. E., and Ratcliffe, J. M. (2017). "Body Size Predicts Echolocation Call Peak Frequency Better than Gape Height in Vespertilionid Bats,” Sci. Rep., , doi: 10.1038/s41598-017-00959-2. doi:10.1038/s41598-017-00959-2

Trappe, M., and Schnitzler, H.-U. (1982). "Doppler-Shift Compensation in Insect-Catching Horseshoe Bats," Naturwissenschaften, 62, 193-194.

Voigt, C. C., Currie, S. E., Fritze, M., Roeleke, M., and Lindecke, O. (2018). “Conservation Strategies for Bats Flying at High Altitudes,” BioScience, 68, 427-435.

Waters, D. A., Rydell, J., and Jones, G. (1995). "Echolocation Call Design and Limits on Prey Size: A Case Study Using the Aerial-Hawking Bat Nyctalus leisleri,” Behav. Ecol. Sociobiol., 37, 321-328. 
563 Williams, T. C., Ireland, L. C., and Williams, J. M. (1973). "High Altitude Flights of the FreeTailed Bat, Tadarida brasiliensis, Observed with Radar,” J. Mammal., 54, 807-821. doi:10.2307/1379076

\section{TABLES}

568 Table 1 - Summary statistics for mean acoustic parameters (from Barataud, 2017, 2015), 569 mean morphological variables and predicted proportion of flight at height. Species names are 570 given with the first three letters of genus and species. CF: constant frequencies. FM: 571 frequency modulated. QFC: quasi-constant frequencies. $\mathrm{N}$ calls $=$ Number of calls measured 572 in Barataud (2017). $\mathrm{N}$ flights = number of acoustic sequences used to calculate the proportion 573 of flights at height. ARI: aspect ratio index for bat wings. WLI: wing loading index. See 574 Table 4 for details about the morphological values used to calculate ARI and WLI.

\begin{tabular}{|c|c|c|c|c|c|c|c|c|c|c|}
\hline Species & Group & Call type & $\begin{array}{c}\text { Peak } \\
\text { frequency } \\
(\mathrm{kHz})\end{array}$ & $\begin{array}{c}\text { Duration } \\
\text { (ms) }\end{array}$ & $\begin{array}{c}\text { Bandwidth } \\
\text { (kHz) }\end{array}$ & $\begin{array}{c}N \\
\text { calls }\end{array}$ & $A R I$ & $\begin{array}{c}W L I \\
\left(10^{-4}\right)\end{array}$ & \begin{tabular}{|}
$\begin{array}{c}\text { Proportion } \\
\text { of flights at } \\
\text { height }\end{array}$ \\
\end{tabular} & $\begin{array}{c}N \\
\text { flights }\end{array}$ \\
\hline Barbar & & $\mathrm{FM}$ & 37.85 & 4.11 & 16.85 & 55 & 2.12 & 7.87 & 0.00 & 6798 \\
\hline Eptnil & & FM/QFC & 28.59 & 13.18 & 8.41 & 167 & 2.09 & 10.31 & 0.15 & 169 \\
\hline Eptser & & FM/QFC & 30.40 & 8.38 & 26.75 & 225 & 2.20 & 11.91 & 0.06 & 13309 \\
\hline Hypsav & & FM/QFC & 34.28 & 9.54 & 13.11 & 81 & 2.17 & 8.94 & 0.23 & 8252 \\
\hline Minsch & & FM/QFC & 53.27 & 9.20 & 23.48 & 114 & 2.48 & 8.97 & 0.01 & 1835 \\
\hline Myobec & \multirow{3}{*}{$\begin{array}{l}\text { Small } \\
\text { Myotis }\end{array}$} & FM & 49.70 & 4.67 & 67.57 & 220 & 2.02 & 7.35 & \multirow{3}{*}{0.00} & \multirow{3}{*}{16560} \\
\hline Myodau & & FM & 47.91 & 4.17 & 60.02 & 201 & 2.12 & 9.11 & & \\
\hline Myonat & & FM & 54.39 & 4.07 & 83.79 & 172 & 2.05 & 7.38 & & \\
\hline Myobly & \multirow{2}{*}{$\begin{array}{l}\text { Large } \\
\text { Myotis }\end{array}$} & FM & 39.85 & 5.27 & 58.50 & 124 & 2.09 & 10.40 & \multirow{2}{*}{0.02} & \multirow{2}{*}{1213} \\
\hline Myomyo & & FM & 40.04 & 5.58 & 58.47 & 231 & 2.11 & 9.79 & & \\
\hline Nyclas & & FM/QFC & 16.70 & 20.82 & 6.99 & 166 & 2.48 & 17.33 & 0.72 & 49 \\
\hline Nyclei & & FM/QFC & 25.59 & 10.82 & 8.26 & 123 & 2.48 & 14.15 & 0.49 & 27204 \\
\hline Nycnoc & & FM/QFC & 22.30 & 14.50 & 8.10 & 170 & 2.75 & 16.80 & 0.31 & 4845 \\
\hline Pipkuh & & FM/QFC & 38.09 & 7.64 & 15.02 & 142 & 2.15 & 8.37 & 0.10 & 56011 \\
\hline Pipnat & & FM/QFC & 40.35 & 7.65 & 11.80 & 123 & 2.12 & 9.55 & 0.19 & 10832 \\
\hline Pippip & & FM/QFC & 46.82 & 6.86 & 20.16 & 153 & 2.16 & 7.61 & 0.08 & 403619 \\
\hline Pippyg & & FM/QFC & 54.98 & 6.71 & 12.71 & 143 & 2.21 & 9.36 & 0.04 & 10709 \\
\hline Pleaur & \multirow{2}{*}{$\begin{array}{c}\text { Plecotus } \\
\text { spp. }\end{array}$} & $\mathrm{FM}$ & 34.40 & 3.40 & 27.60 & 224 & 2.06 & 7.13 & \multirow{2}{*}{0.00} & \multirow{2}{*}{7736} \\
\hline Pleaus & & $\mathrm{FM}$ & 30.90 & 3.30 & 19.70 & 216 & 2.09 & 7.23 & & \\
\hline
\end{tabular}




\begin{tabular}{|l|c|c|c|c|c|c|c|c|c|c|}
\hline Rhifer & & CF+FM & 82.40 & 45.00 & 16.00 & 53 & 2.06 & 10.40 & 0.00 & 218 \\
\hline Rhihip & & CF+FM & 109.40 & 45.00 & 22.00 & 129 & 1.84 & 5.99 & 0.00 & 14 \\
\hline Tadten & & FM/QFC & 12.14 & 15.06 & 4.54 & 115 & 2.97 & 12.73 & 0.48 & 16671 \\
\hline Vesmur & & FM/QFC & 25.59 & 13.27 & 11.11 & 155 & 2.31 & 10.38 & 0.86 & 72 \\
\hline
\end{tabular}

576 Table 2 - Kendall's correlation tests between all acoustic variables. ARI: aspect ratio index

577 for bat wings. WLI: wing loading index. NS: not significant.

\begin{tabular}{|l|l|l|l|}
\hline Variable 1 & Variable 2 & tau & p-value \\
\hline Peak & Duration & -0.22 & NS \\
\hline Peak & Bandwidth & 0.50 & $<0.001$ \\
\hline Duration & Bandwidth & -0.51 & $<0.001$ \\
\hline ARI & Peak & -0.45 & $<0.005$ \\
\hline ARI & Duration & 0.37 & $<0.05$ \\
\hline ARI & Bandwidth & -0.51 & $<0.001$ \\
\hline WLI & Peak & -0.41 & $<0.01$ \\
\hline WLI & Duration & 0.48 & $<0.005$ \\
\hline WLI & Bandwidth & -0.46 & $<0.005$ \\
\hline WLI & ARI & 0.46 & $<0.005$ \\
\hline
\end{tabular}

579 Table 3 - Kendall's correlation tests between rate of flight at height and acoustic variables.

580 ARI: aspect ratio index for bat wings. WLI: wing loading index.

\begin{tabular}{|l|l|l|l|}
\hline Variable 1 & Variable 2 & tau & p-value \\
\hline \multirow{4}{*}{ Rate of flight at height } & Peak & -0.59 & $<0.001$ \\
\cline { 2 - 4 } & Duration & 0.44 & $<0.005$ \\
\cline { 2 - 4 } & Bandwidth & -0.56 & $<0.001$ \\
\cline { 2 - 4 } & ARI & 0.58 & $<0.001$ \\
\cline { 2 - 4 } & WLI & 0.48 & $<0.005$ \\
\hline
\end{tabular}

\section{FIGURE CAPTIONS}

584 Figure 1 - Correlation between the predicted proportion of flight at height and morphological 585 and sonar variables. Etiquettes relate to the first three letters of genera and species names. The 
586

categories CF (constant frequencies), FM (frequency modulated), and QFC (quasi-constant frequencies) refer to the acoustic strategy of the different species. The linear regression line is shown. Acoustic parameters are presented on a logarithmic scale. Wing drawings represent the extreme values.

\section{SUPPLEMENTARY FIGURE CAPTIONS}

Figure 2 - Microphone heights for each study site. Open circles show microphone height and filled circles show the median height.

Figure 3 - Influence of microphone median height on the proportion of bat flights at height. The regression line is shown (modelled with a binomial generalized linear model with microphone median height and species as fixed effect). Species names are given with the first three letters of species and genus. $95 \%$ confidence intervals are shown.

\section{APPENDIX}

Table 4 - Mean morphological values used to calculate ARI (aspect ratio index for bat wings) and WLI (wing loading index). These values were retrieved from Dietz et al. (2009). Species names are given with the first three letters of genus and species.

Species Group Forearm length Length of $5^{\text {th }}$ Length of $3^{\text {rd }}$ Mass 


\begin{tabular}{|c|c|c|c|c|c|}
\hline & & $(\mathrm{mm})$ & $\operatorname{digit}(\mathrm{mm})$ & $\operatorname{digit}(\mathrm{mm})$ & (g) \\
\hline Barbar & & 40.00 & 50.50 & 67.00 & 8.50 \\
\hline Eptnil & & 40.65 & 50.50 & 65.00 & 11.00 \\
\hline Eptser & & 53.00 & 64.00 & 88.00 & 21.50 \\
\hline Hypsav & & 34.65 & 42.50 & 57.50 & 7.00 \\
\hline Minsch & & 45.20 & 52.00 & 83.50 & 12.00 \\
\hline Myobec & \multirow{3}{*}{$\begin{array}{l}\text { Small } \\
\text { Myotis }\end{array}$} & 43.05 & 53.50 & 65.00 & 8.50 \\
\hline Myodau & & 37.55 & 45.50 & 59.00 & 8.00 \\
\hline Myonat & & 39.20 & 53.00 & 69.50 & 8.50 \\
\hline Myobly & \multirow{2}{*}{$\begin{array}{l}\text { Large } \\
\text { Myotis }\end{array}$} & 56.30 & 72.00 & 94.00 & 22.50 \\
\hline Myomyo & & 60.95 & 75.50 & 98.00 & 23.50 \\
\hline Nyclas & & 65.50 & 71.50 & 112.00 & 44.00 \\
\hline Nyclei & & 42.55 & 47.00 & 74.00 & 15.50 \\
\hline Nycnoc & & 53.10 & 52.50 & 91.50 & 25.50 \\
\hline Pipkuh & & 33.85 & 42.50 & 57.50 & 6.50 \\
\hline Pipnat & & 34.65 & 44.50 & 59.50 & 8.00 \\
\hline Pippip & & 31.25 & 39.00 & 53.00 & 5.00 \\
\hline Pippyg & & 30.00 & 36.50 & 50.50 & 5.50 \\
\hline Pleaur & \multirow{2}{*}{$\begin{array}{c}\text { Plecotus } \\
\text { spp. }\end{array}$} & 39.15 & 50.50 & 65.00 & 7.50 \\
\hline Pleaus & & 40.00 & 51.50 & 67.50 & 8.00 \\
\hline Rhifer & & 57.70 & 70.00 & 86.50 & 21.00 \\
\hline Rhihip & & 37.85 & 50.00 & 54.00 & 5.50 \\
\hline Tadten & & 62.30 & 57.50 & 108.50 & 25.00 \\
\hline Vesmur & & 45.55 & 51.00 & 72.50 & 12.50 \\
\hline
\end{tabular}

606 